\title{
Altering endocannabinoid neurotransmission at critical developmental ages: impact on rodent emotionality and cognitive performance
}

\section{Viviana Trezza ${ }^{1}$, Patrizia Campolongo ${ }^{2}$, Antonia Manduca ${ }^{1}$, Maria Morena ${ }^{2}$, Maura Palmery ${ }^{2}$, Louk J. M. J. Vanderschuren ${ }^{3,4}$ and Vincenzo Cuomo ${ }^{2}$}

' Department of Biology, University "Roma Tre," Rome, Italy

${ }^{2}$ Department of Physiology and Pharmacology, University of Rome Sapienza, Rome, Italy

${ }^{3}$ Department of Neuroscience and Pharmacology, Rudolf Magnus Institute of Neuroscience, University Medical Center Utrecht, Utrecht, Netherlands

${ }^{4}$ Department of Animals in Science and Society, Division of Behavioural Neuroscience, Faculty of Veterinary Medicine, Utrecht University, Utrecht, Netherlands

\section{Edited by:}

Martine Ammassari-Teule,

Consiglio Nazionale delle

Ricerche, Italy

Reviewed by:

Francoise Schenk, Université de Lausanne, Switzerland

Emma Louise Lane,

Cardiff University, UK

*Correspondence:

Viviana Trezza, Department of Biology, University "Roma Tre,"

Viale G. Marconi 446, 00146 Rome,

Italy.e-mail:vtrezza@uniroma3.it
The endocannabinoid system shows functional activity from early stages of brain development: it plays an important role in fundamental developmental processes such as cell proliferation, migration, and differentiation, thus shaping brain organization during pre-and postnatal life. Cannabis sativa preparations are among the illicit drugs most commonly used by young people, including pregnant women. The developing brain can be therefore exposed to cannabis preparations during two critical periods: first, in offspring of cannabis-using mothers through perinatal and/or prenatal exposure; second, in adolescent cannabis users during neural maturation. In the last decade, it has become clear that the endocannabinoid system critically modulates memory processing and emotional responses. Therefore, it is well possible that developmental exposure to cannabinoid compounds induces enduring changes in behaviors and neural processes belonging to the cognitive and emotional domains. We address this issue by focusing on rodent studies, in order to provide a framework for understanding the impact of cannabinoid exposure on the developing brain.

Keywords: endocannabinoid system, behavior, development, emotion, cognition, pregnancy, adolescence

\section{INTRODUCTION}

The endocannabinoid system consists of two types of G-proteincoupled receptors $\left(\mathrm{CB}_{1}\right.$, highly expressed in the brain, and $\mathrm{CB}_{2}$, more abundant in immune cells), their endogenous lipid ligands, and the enzymatic machinery for their synthesis and degradation (Piomelli, 2003; Di Marzo et al., 2005; De Petrocellis and Di Marzo, 2009). Endogenous ligands for cannabinoid receptors, i.e., endocannabinoids [mainly anandamide and 2arachidonoylglycerol (2-AG)], are synthesized on demand in an activity-dependent manner and released from postsynaptic neurons (Freund etal., 2003; Piomelli, 2003). Once released into the synaptic cleft, the newly synthesized endocannabinoids travel in retrograde direction and bind to cannabinoid receptors on presynaptic terminals (Freund etal., 2003; Piomelli, 2003). The primary consequences of activation of cannabinoid receptors are regulation of ion channel activity and neurotransmitter release (Szabo and Schlicker, 2005). Thus, by acting on cannabinoid receptors on both excitatory and inhibitory terminals, endocannabinoids play a major role in several forms of short- and long-term synaptic plasticity (Freund et al., 2003; Piomelli, 2003; Chevaleyre et al., 2006). Endocannabinoid modulation of synaptic activity affects several biological functions, including regulation of emotionality and cognitive performance (Wotjak, 2005; Moreira and Lutz, 2008; Campolongo etal., 2009a,b; Lutz, 2009; Akirav, 2011; Marco et al., 2011; Rubino and Parolaro, 2011; Terzian et al., 2011; Zanettini et al., 2011). It has indeed repeatedly been shown that cannabis exposure produces a wide range of subjective emotional effects in humans (Tunving, 1985; Williamson and Evans, 2000; Degenhardt et al., 2003; Di Forti etal., 2007; Murray etal., 2007; Fattore and Fratta, 2011). Furthermore, many clinical studies have reported that acute challenges with or prolonged use of cannabis and its products may impair attentional processing and working memory in humans (Iversen, 2003; Ranganathan and D'Souza, 2006; Pattij etal., 2008; Solowij and Pesa, 2010; Fattore and Fratta, 2011). These observations have their counterpart in animal studies, showing that cannabinoid compounds elicit dose-dependent and environment-dependent anxiolytic and anxiogenic effects in rodent models of anxiety (Onaivi et al., 1990; Rodriguez de Fonseca et al., 1996, 1997; Haller et al., 2002, 2004a,b; Martin et al., 2002; Kathuria et al., 2003; Wotjak, 2005; Bortolato et al., 2006; Moreira et al., 2008; Marco et al., 2011), and affect learning and memory in rodents (Castellano etal., 2003; Riedel and Davies, 2005; Wotjak, 2005; Schneider et al., 2008; Suenaga and Ichitani, 2008; Baek etal., 2009; Marsicano and Lafenetre, 2009; Akirav, 2011).

In both humans and rodents, the endocannabinoid system is present and active in the central nervous system (CNS) 
from early developmental ages (Berrendero etal., 1998; Fernandez-Ruiz etal., 2000; Mato etal., 2003; Fride, 2004; Galve-Roperh et al., 2006; Harkany et al., 2007) and continues to develop throughout adolescence (Rodriguez de Fonseca et al., 1993; Belue et al., 1995; Romero et al., 1997; Berrendero et al., 1999). Therefore, developmental exposure to cannabinoid compounds can have profound effects on brain architecture, chemistry and neurobehavioral function, by changing for instance neurotransmitter levels, and by modulating expression of their receptors, transporters, and degrading enzymes.

Developmental studies on the effects of cannabinoid drugs are of special relevance for two main reasons. First, cannabis preparations are the illicit drugs most widely used by young people, peaking between 15 and 30 years of age (NIDA, 2005; Hall and Degenhardt, 2009; SAMHSA, 2009). Importantly, there is an emerging trend for continued cannabis use in people aged 30-40 (NIDA, 2005; SAMHSA, 2009). This pattern of use potentially exposes the developing brain to cannabis at two periods: first, in offspring of cannabis-using mothers during the perinatal and/or prenatal period; second, in adolescent cannabis users during neural maturation. Therefore, a better understanding of the mechanisms by which exposure to cannabinoid drugs during development leads to neurobehavioral alterations or induces neuropsychiatric disorders later in life is an important issue. Furthermore, in addition to the well-known therapeutic effects of drugs directly acting at cannabinoid receptors (e.g., as appetite stimulants, anti-emetics, analgesics in neuropathic pain; Pacher et al., 2006; Di Marzo, 2009; Bermudez-Silva et al., 2010), the endocannabinoid system is now emerging as a novel therapeutic target for the treatment of the emotional and cognitive disturbances that characterize some neuropsychiatric disorders (Piomelli et al., 2006; Vinod and Hungund, 2006; Petrosino and Di Marzo, 2010; Marco et al., 2011), including neurodevelopmental disorders. However, the potential therapeutic application of cannabinoid drugs in young populations requires a profound investigation of possible adverse effects of such compounds, particularly on the CNS of immature individuals.

In order to provide a deeper understanding of the longlasting, subtle neurobehavioral effects of developmental exposure to cannabinoid drugs, and to adopt effective public health strategies, it is critical to stimulate a dialog between human and animal studies. While studies in humans are, of course, most relevant for understanding the human situation, they can only provide limited information about the specific molecular and cellular consequences that underlie drug-induced behavioral and neural changes. The important advantage of animal studies is that they allow for exquisite control over the possible confounding factors that characterize human studies, and for examination of the independent contribution of a certain drug to adverse neurodevelopmental consequences.

Here, we examine and discuss preclinical evidence for how cannabinoid exposure during critical developmental ages, such as the perinatal, prenatal, and adolescent periods, affects emotionality and cognitive performance in rodents, thus providing a framework for understanding the impact of cannabinoid exposure on the developing brain.

\section{EFFECTS OF DEVELOPMENTAL EXPOSURE TO CANNABINOIDS ON COGNITIVE PERFORMANCE IN RODENTS PRENATAL AND PERINATAL CANNABINOID EXPOSURE}

First, we will briefly summarize the results of human studies that investigated the consequences of developmental exposure to cannabinoids on cognitive performance, and then we will focus on rodent studies.

Since the late 1970s, two extended longitudinal cohort studies, the Ottawa Prenatal Prospective Study (OPPS) and the Maternal Health Practices and Child Development Study (MHPCD), have been measuring the cognitive functions of children born from mothers who consumed Cannabis sativa preparations during pregnancy (Day et al., 1992; Fried, 2002b; Trezza et al., 2008b; Campolongo et al., 2009c, 2010). These studies showed that the consequences of prenatal exposure to cannabis are rather subtle. Immediately after birth, there is little evidence for a prenatal cannabis effect either upon growth or behavior (Fried and Watkinson, 1988). However, beyond the age of 3 , there are findings suggesting an association between prenatal cannabis exposure and aspects of cognitive behavior that fall in the domain of executive functions (Fried and Watkinson, 1990; Day etal., 1992, 1994; Fried et al., 1998; Fried and Smith, 2001; Fried, 2002b; Trezza et al., 2008b). Executive functions refer to higher-order cognitive functions such as cognitive flexibility, sustained and focused attention, planning and working memory. These functions enable us to organize and manage the many tasks in our daily life; for instance, to account for short- and long-term consequences of our actions, to make real time evaluations of our actions, and make necessary adjustments if these actions are not achieving the desired results. Impairments in executive functions have a major impact on our ability to perform tasks as planning, prioritizing, organizing, paying attention to and remembering details, and controlling our emotional reactions. In particular, the facets of executive functions which appear to be affected by cannabis exposure are the domains of attention/impulsivity and problem solving situations requiring integration and manipulation of basic visuoperceptual skills (Fried and Watkinson, 1990; Day et al., 1992, 1994; Fried et al., 1998; Fried and Smith, 2001; Fried, 2002b; Trezza et al., 2008b). The deficits in executive functions induced by prenatal cannabis exposure seem to be long-lasting, since 18 - to 22 -year-old young adults exposed to cannabis during pregnancy showed altered neuronal functioning during visuospatial working memory processing (Smith et al., 2006).

Although there is a convergence of evidence in human studies, the very limited number of studies which have followed children beyond the age of 3 emphasizes the need for further, well-controlled investigations in this area. Furthermore, it cannot be excluded from human studies that genetic and environmental variables also contribute to the relationship between maternal cannabis use and long-term cognitive deficits in the offspring. Therefore, the long-term effects of prenatal exposure to cannabinoid drugs on cognitive functions in rodents have received a great deal of attention. Prenatal exposure to a moderate dose of the synthetic $\mathrm{CB}_{1}$ cannabinoid receptor agonist WIN55,212$2(0.5 \mathrm{mg} / \mathrm{kg}$ from GD 5 to GD 20) has been shown to induce 
a disruption of memory retention in 40- and 80-day-old rat offspring tested in the inhibitory avoidance task (Mereu et al., 2003). This cognitive impairment was not due to alterations of non-associative nature, since the approach latency during the acquisition trials of the task was unaffected. The memory impairment in WIN55,212-2-exposed offspring was associated with alterations in hippocampal long-term potentiation (Mereu et al., 2003). In vivo microdialysis experiments also showed a significant decrease in basal and $\mathrm{K}^{+}$-evoked extracellular glutamate levels in the hippocampus of juvenile and adult rats born from WIN55,212-2-treated dams (Mereu et al., 2003). The decrease in hippocampal glutamate overflow was suggested to be the cause of disrupted long-term potentiation, which could, in turn, underlie the long-lasting memory impairment caused by gestational exposure to the cannabinoid receptor agonist (Mereu et al., 2003). To further support the hypothesis that changes in glutamatergic neurotransmission might be responsible of the cognitive impairment observed in WIN55,212-2-exposed offspring, in vivo microdialysis experiments showed that basal and $\mathrm{K}^{+}$evoked glutamate levels were significantly lower in the cerebral cortex of both adult (90-day-old) and adolescent (40-day-old) rats exposed to WIN55,212-2 during gestation than in those born from vehicle-treated mothers (Antonelli et al., 2004; Castaldo et al., 2007; Ferraro etal., 2009). Interestingly, the cognitive deficits induced by prenatal exposure to WIN55,212-2 appeared already at early developmental ages. Thus, 10- to 12-day-old WIN55,212-2exposed pups showed a poorer performance in homing behavior, a simple form of learning occurring during the early phases of postnatal life (Antonelli et al., 2005). At the neurochemical level, basal and $\mathrm{K}^{+}$-evoked glutamate levels were significantly lower in primary cell cultures of hippocampus (Mereu et al., 2003) and cerebral cortex (Antonelli et al., 2005, 2006) obtained from pups exposed to WIN55,212-2 compared to pups from the control group. The alteration of cortical glutamate transmission induced by prenatal WIN55,212-2 exposure was also associated with a significant reduction of NMDA receptor-mediated regulation of glutamate levels (Ferraro et al., 2009). In fact, the NMDA-induced concentration-dependent increase of glutamate levels observed in cortical cell cultures obtained from neonates born from vehicle-treated dams was completely lost in cell cultures obtained from pups prenatally exposed to WIN55,212-2 (Antonelli etal., 2005). These results suggest that chronic prenatal treatment with WIN55,212-2 induces a loss of NMDA receptor activity in the exposed offspring (Antonelli et al., 2005; Ferraro et al., 2009).

Morphological experiments have shown that prenatal exposure to WIN55,212-2 also affects neuronal proliferation: a different neurite growth pattern was observed in cortical cell cultures obtained from pups born from mothers exposed to WIN55,2122 during pregnancy (Antonelli et al., 2005; Ferraro et al., 2009). Cortical cell cultures from vehicle-exposed pups showed a high number of healthy neurons, which developed in a monolayer to form a complex network of neurites. On the contrary, cortical cultures obtained from pups exposed to WIN55,212-2 during pregnancy showed a minor population of neurons and abnormal neurite outgrowth, characterized by impairments of neurite branching (Antonelli et al., 2005; Ferraro et al., 2009).
Exposure to cannabinoid agonists during critical periods of brain development is known to cause long-term changes in the functionality of several neurotransmitter systems in adulthood, such as alterations in dopaminergic (Rodriguez de Fonseca et al., 1991; Bonnin et al., 1994, 1995), opioidergic (Vela et al., 1995, 1998), serotonergic (Molina-Holgado et al., 1996), and GABAergic (Garcia-Gil et al., 1999a) systems. In addition, prenatal exposure to WIN55,212-2 has been found to induce long-term changes in the activity of the endocannabinoid system: in particular, the functionality of $\mathrm{CB}_{1}$ receptors in the hippocampus differed between adult WIN55,212-2- and vehicle-exposed offspring (Castelli et al., 2007). Thus, it can be speculated on basis of the in vitro and in vivo results that gestational WIN55,212-2-exposure produces enduring alterations of the endocannabinoid system in the developing brain, which may lead to a long-lasting and irreversible disruption of glutamate cortical and hippocampal function (Castelli et al., 2007; Ferraro et al., 2009).

As for the clinical relevance of these preclinical studies, it is important to estimate, by extrapolation, whether the dose of the synthetic cannabinoid agonist WIN55,212-2 is comparable to that of the main active ingredient of cannabis, $\Delta$ 9-tetrahydrocannabinol (THC), absorbed by cannabis users. It has been estimated that a dose of $5 \mathrm{mg} / \mathrm{kg}$ of THC in rats corresponds to a moderate exposure to the drug in humans, correcting for the differences in route of administration and body weight surface area (Garcia-Gil et al., 1997, 1999a,b). WIN55,212-2 has been found to be $3-10$ times more potent than THC, depending on the administration route and the behavioral endpoints considered (Compton et al., 1992; French et al., 1997; Hampson et al., 2000). This mirrors the $\mathrm{CB}_{1}$ receptor affinity rank order for the two drugs (Matsuda, 1997; Pertwee, 1997). Based on these considerations, the dose of WIN55,212-2 used in the studies described above corresponds to a moderate, or even to a low, exposure to cannabis in humans (Mereu et al., 2003). Furthermore, in line with studies that used a protocol of prenatal WIN55,212-2 exposure, it has been demonstrated that the active ingredient of cannabis, THC, administered during the perinatal period at a dose $(5 \mathrm{mg} / \mathrm{kg}$, per os, from GD 15 to PND 9) that is not associated with gross malformations and/or overt signs of toxicity, induces cognitive impairments in the adult offspring (Campolongo et al., 2007). Importantly, perinatal exposure to THC not only induced a long-term memory impairment in the adult offspring, as revealed by the inhibitory avoidance test, but also a disruption in short-term olfactory memory, as assessed in the social discrimination test (Campolongo et al., 2007). This form of memory, that plays a crucial role in the processing of social information, requires integral glutamatergic projections from the hippocampal formation to prefrontal areas (Steckler etal., 1998; McGaugh, 2002), and then back from the prefrontal cortex to the hippocampus. Interestingly, the cognitive impairments observed in THC-exposed adult offspring were associated with long-lasting alterations in the cortical expression of genes related to glutamatergic neurotransmission, together with a decrease in the cortical extracellular levels of this neurotransmitter (Campolongo et al., 2007). Furthermore, in line with studies that used a protocol of prenatal WIN55,212-2 exposure, the neurochemical changes induced by prenatal THC exposure appeared early in development, as altered regulation of glutamate release and 
decreased functional activity and expression of GLT1 and GLAST glutamate transporters in the hippocampus of adolescent rats perinatally exposed to THC have been reported (Castaldo et al., 2010). Again, these studies strongly suggest that changes in glutamatergic neurotransmission might be responsible for the cognitive deficits induced by prenatal cannabinoid exposure.

\section{ADOLESCENT CANNABINOID EXPOSURE}

In most Western Countries, the first episodes of cannabis use often occur during adolescence (NIDA, 2005; Hall and Degenhardt, 2009; SAMHSA, 2009). Adolescence is a critical phase for CNS development during the transition from childhood to adulthood (Spear, 2000; Andersen, 2003). It is a period characterized by widespread neuronal plasticity and maturation at the neural and network level, when the brain undergoes both progressive and regressive changes including extensive synaptic remodeling and pruning and alterations in neurotransmitter levels and their receptors in cortical and limbic brain regions across different species (Spear, 2000; Andersen, 2003), processes in which the endocannabinoid system plays a major role (Spear, 2000; Andersen, 2003; Freund et al., 2003; Bossong and Niesink, 2011; Rubino et al., 2011).

Both neuropsychological and functional imaging studies indicate that the detrimental effects of cannabis on cognitive performance may be more pronounced when cannabis is used during adolescence (Ehrenreich et al., 1999; Jager and Ramsey, 2008; Schweinsburg etal., 2008; Bossong and Niesink, 2011). Most imaging studies in adolescent subjects reported cannabisinduced alterations in working memory (Jacobsen et al., 2004, 2007; Schweinsburg et al., 2008). Studies making a distinction between the initiation of cannabis use in adolescence and in adult life showed attention deficits and poor cognitive performance in early-onset cannabis users (onset before age 17), but not in lateonset users or control subjects (Ehrenreich et al., 1999; Pope Jr. et al., 2003).

Despite the increasing use of cannabis among adolescents and the sometimes conflicting results provided by clinical studies, it is only in recent years that the short- and long-term behavioral effects of acute and chronic adolescent exposure to cannabinoid compounds in rodents have been investigated in more detail (Rubino and Parolaro, 2008; Trezza et al., 2008b; Realini et al., 2009; Rubino et al., 2011).

Quinn etal. (2008) showed that adolescent but not adult rats displayed significantly impaired object recognition memory and altered protein expression profiles in the hippocampus following repeated THC exposure. Similarly, Schneider and Koch (2003) showed that chronic pubertal treatment with WIN55,2122 resulted in impaired object recognition memory in adulthood, associated with disrupted prepulse inhibition of the acoustic startle response and lower break points in a progressive-ratio operant behavioral task (Schneider and Koch, 2003). Again, it is worth noting that if the chronic cannabinoid treatment was administered during adulthood, none of the tested behaviors was affected (Schneider and Koch, 2003). Gender-specific effects of chronic adolescent cannabinoid exposure have also been reported (O'Shea et al., 2004, 2006). In these studies, the cannabinoid receptor agonist CP-55,940 was administered daily for 21 consecutive days to either adolescent or adult male and female rats. Following a long drug-free period, working memory was assessed in the object recognition task (O'Shea et al., 2004, 2006). In females, cannabinoid-treated adolescent, but not adult rats demonstrated impaired working memory compared to vehicle-treated controls (O'Shea et al., 2004, 2006). Interestingly, in males, cannabinoid treatment during adolescence and adulthood produced similar working memory deficits (O'Shea et al., 2004). Thus, in females, adolescents may be more susceptible and adults more resilient to long-lasting cannabinoid-induced cognitive deficits, whereas in males, both adolescents and adults are equally vulnerable. Deficits in object recognition memory have also been reported in adult female rats treated chronically with THC during adolescence (Realini et al., 2011).

Developmental and gender sensitivity to cannabinoid compounds has been further investigated by Cha et al. $(2006,2007)$, who assessed spatial memory in the Morris water maze task following acute and chronic THC exposure in male and female adolescent and adult rats. Acute THC exposure led to greater learning impairments in adolescent than in adult male and female rats tested in both the spatial and non-spatial versions of the water maze tasks (Cha et al., 2006, 2007). Conversely, chronic THC administration during either adolescence or adulthood had no effect on spatial learning in animals of both sexes tested after a long drug-free period (Cha et al., 2006, 2007). Thus, while adolescents may be more sensitive to the acute effects of cannabinoids, both adolescents and adults demonstrated similar recovery of cognitive performance following discontinuation of chronic treatment (Cha et al., 2006, 2007). In line with these findings, it has been reported that adolescent exposure to the cannabinoid receptor agonist CP55,940 did not affect adult performance of animals of both sexes in the water maze task (Higuera-Matas et al., 2009). However, following adolescent exposure to THC, spatial working memory in the radial maze task was impaired in both male and female adult rats, while aversive memory in the inhibitory avoidance task was unaffected (Rubino et al., 2009a,b). The neural underpinnings of the spatial working memory impairments observed in the latter studies may differ between males and females (Rubino and Parolaro, 2011). Indeed, adult female rats showed reduced levels of proteins involved in synaptic plasticity and altered pattern of protein expression in synaptosomes from prefrontal cortex, with no alterations in the hippocampus (Rubino et al., 2009a). Conversely, in adult male rats pre-exposed to THC during adolescence, the spatial working memory deficit was related to reduced levels of markers of neuroplasticity and morphological alterations in the hippocampus (Rubino et al., 2009b). These results suggest that the same protocol of adolescent THC exposure, although resulting in similar behavioral endpoints, may have different neuronal consequences in the brain of male or female rats.

Long-term sexually dimorphic effects induced by adolescent THC exposure on cognitive performance have also been described by Harte and Dow-Edwards (2010), who examined the effects of adolescent THC exposure on visual spatial learning in adulthood using the active place avoidance test. This cognitive task allows to simultaneously assess the ability to learn and retrieve spatial information, as well as flexibility of learning, by training animals to actively move over a slowly rotating arena and avoid an unmarked 
sector, entering which is punished by a mild footshock. The shock sector is defined in a stable position with respect to the experimental room. Animals must thus localize the shock sector exclusively by its spatial relations to distal orienting cues located in the room and walk into the safe part of the arena in a direction opposite to arena rotation (Cimadevilla et al., 2000). By using this task, Harte and Dow-Edwards (2010) showed that THC administration during early adolescence had no effect on the acquisition of the task. However, male and female animals treated with THC during early adolescence made more errors on the reversal trial requiring flexibility in learning. Conversely, THC administration during late adolescence had no effect in both sexes. Therefore, early adolescence appeared to be more sensitive to the cognitive effects of THC than late adolescence (Harte and Dow-Edwards, 2010). These findings indicate that the time window during adolescence in which THC is administered can have a profound influence on its long-lasting cognitive outcomes.

\section{SUMMARY}

Taken together, the preclinical studies outlined here show that maternal and adolescent exposure to either natural or synthetic cannabinoid agonists alters cognitive performance in the offspring. The cognitive alterations displayed by cannabinoid-treated rats are long-lasting, since they persist into adulthood. Furthermore, in line with clinical observations, it appears from preclinical studies that adolescent rats may be more susceptible than adults to the cognitive effects induced by chronic exposure to cannabinoid compounds.

\section{EFFECTS OF DEVELOPMENTAL EXPOSURE TO CANNABINOIDS ON EMOTIONALITY IN RODENTS PRENATAL AND PERINATAL CANNABINOID EXPOSURE}

Although C. sativa preparations have long been known to produce a wide range of subjective emotional effects, it is only in recent years that the crucial role of the endocannabinoid system in the modulation of emotional states has been underscored (Haller et al., 2002; Millan, 2003; Witkin et al., 2005; Mangieri and Piomelli, 2007; Trezza et al., 2008a; Bambico et al., 2009; Marco and Viveros, 2009; Marco et al., 2011; Zanettini et al., 2011). It has, indeed, been shown that $\mathrm{CB}_{1}$ cannabinoid receptors are highly expressed in brain areas involved in the modulation of emotions (Tsou et al., 1998; Ameri, 1999; Davies et al., 2002). In these regions, endocannabinoids modulate the release of neurotransmitters and neuropeptides that play a key role in the control of emotionality, such as serotonin, dopamine (Tsou et al., 1998; Katona et al., 2001; Schlicker and Kathmann, 2001; Hermann et al., 2002) and the anxiogenic neuropeptides, CCK and CRF (Rodriguez de Fonseca et al., 1997; Ameri, 1999). Therefore, it is well conceivable that in utero cannabis exposure might produce changes in the emotional reactivity of the exposed offspring. Human studies support this hypothesis, by showing that prenatal exposure to cannabis in the first and third trimesters of pregnancy predicts levels of self-reported anxiety and depressive symptoms in children (Goldschmidt et al., 2004; Gray et al., 2005; Leech et al., 2006). Again, however, only few clinical studies followed the exposed children past the age of 10 (Fried, 2002a,b; Fried et al., 2003; Goldschmidt et al., 2004; Gray et al., 2005; Leech etal., 2006), so that most of the available information about the long-term consequences of in utero cannabis exposure on the emotional reactivity of the offspring comes from preclinical studies.

Concerning the neonatal age, we found that 12-day-old pups exposed to THC during the perinatal period displayed an increased rate of ultrasonic vocalizations (USVs) when separated from the mother and siblings compared to the control group (Trezza et al., 2008a). The USV test has been extensively validated and widely used to investigate the ontogeny of emotionality (Insel et al., 1986; Cuomo et al., 1987; Branchi et al., 2001, 2004). USVs are emitted by rodent pups in response to separation from the mother and the nest and play an important communicative role in mother-offspring interaction. They are, indeed, a potent stimulus for maternal retrieval and elicit caregiving behaviors in the dam (Farrell and Alberts, 2002; Trezza et al., 2011). As high rates of USVs are generally indicative of an anxiety-like state, the present results show that perinatal exposure to THC induces an increased emotional reactivity of the offspring (Trezza et al., 2008a). Conversely, a reduction of separation-induced USV in rat pups either prenatally exposed to the synthetic cannabinoid agonist WIN55,212-2 (Antonelli et al., 2005) or acutely treated with the synthetic cannabinoid agonist CP-55,940 (McGregor et al., 1996) has also been reported, highlighting how different time windows of exposure to cannabinoids can induce opposite neurofunctional effects (Costa et al., 2004). However, differences in the cannabinoid agonist used, tested dose, and treatment schedule (acute vs. chronic treatment) could also account for the apparent discrepancies between these preclinical findings. Interestingly, the alterations we observed in the emotional reactivity of THCexposed pups were long-lasting (Trezza et al., 2008a). Indeed, at adolescence, THC-exposed rats displayed lower social activity than controls in the social interaction test (Trezza et al., 2008a). These results are in agreement with findings showing that the synthetic cannabinoid agonist CP-55,940, repeatedly administered from PND 4 to PND 25, reduced social interaction in 60-dayold rats (O'Shea et al., 2006). In adulthood, THC-exposed rats showed increased anxiety in the elevated plus-maze: they spent more time in the closed arms of the maze, exhibited a significantly lower number of head dippings and a higher number of stretchedattend postures than vehicle-exposed rats (Trezza et al., 2008a). The number of total entries, however, was unaffected, indicating that perinatal THC treatment did not alter locomotor activity in the offspring. To further support an altered emotional reactivity induced by perinatal THC exposure, Newsom and Kelly reported that adult rats perinatally exposed to THC spent less time in the central part of an open field arena compared to vehicle-exposed animals, with no changes in general locomotor activity (Newsom and Kelly, 2008).

\section{ADOLESCENT CANNABINOID EXPOSURE}

The possible causal relation between cannabis use during adolescence and psychotic and affective neuropsychiatric diseases later in life is widely debated. While some clinical studies indicate that exposure to cannabis preparations during adolescence may be a risk factor for neuropsychiatric disorders such as schizophrenia, depression, and other mood pathologies (Arseneault et al., 2002; Fergusson et al., 2002, 2003; Patton et al., 2002; Degenhardt et al., 
2003; Stefanis et al., 2004; Hayatbakhsh et al., 2007; Moore et al., 2007; Lee et al., 2008), other authors have found no strong evidence that cannabis use by young people induces deleterious mental health outcomes (Iversen, 2003; Macleod et al., 2004, 2007; de Graaf et al., 2010). Therefore, human studies are still inconclusive as to whether cannabis use during adolescence has a direct causal influence on psychotic, depressive, and/or anxiety disorders later in life, whether cannabis exposure and subsequent psychopathology are related by a common liability, or if the association results from a combination of correlated and causal processes.

\section{ANXIETY-RELATED BEHAVIORS}

Despite the fact that the majority of preclinical studies supports the hypothesis that adolescent exposure to cannabinoid drugs alters emotional reactivity in adulthood, inconsistent and sometimes sex-dependent effects have also been reported (Rubino et al., 2011). For instance, some authors reported no changes in emotional reactivity in animals pretreated with cannabinoid drugs during adolescence and tested in the elevated plus-maze test after a washout period (Rubino et al., 2008; Higuera-Matas et al., 2009; Bambico et al., 2010), while others described cannabinoidinduced anxiolytic-like effects in the same behavioral test (Biscaia et al., 2003; Wegener and Koch, 2009). Contrasting results also emerged from other behavioral tests commonly used to assess emotional reactivity in rodents. For instance, cannabinoid exposure during adolescence induced anxiety-like behaviors in the novelty-suppressed feeding test (Bambico et al., 2010), which assesses anxiety-induced hyponeophagia by measuring the inhibition of ingestion and approach to food when animals are exposed to an anxiety-provoking novel environment. Conversely, no evidence of increased anxiety induced by adolescent cannabinoid exposure was found in adult rats tested in the emergence test (O'Shea et al., 2006), that measures the animal's conflict between exploring a novel environment, and avoiding an open area. When emotionality was assessed by measuring exploratory behavior and the time spent in the central and peripheral parts of an open field arena, some authors reported no effects of adolescent cannabinoid exposure (Rubino et al., 2008; Bambico et al., 2010), while others reported anxiolytic-like responses (Biscaia et al., 2003; Wegener and Koch, 2009).

\section{SOCIAL BEHAVIOR}

More consistent results have been obtained when the social interaction test was used to assess the emotional reactivity of adult rats exposed to cannabinoid drugs during adolescence. The synthetic cannabinoid agonist CP-55,940, administered for 21 days to adolescent rats, reduced social interaction at adulthood, both in male (O'Shea et al., 2006) and female (O'Shea et al., 2004) subjects. Similar results have been reported following chronic adolescent treatment with THC (Realini et al., 2011) or the synthetic cannabinoid receptor agonist WIN55,212-2 (Leweke and Schneider, 2011). There are many internal and external factors that influence an animal's sociability, and anxiety has been identified as one of them (File and Seth, 2003). Therefore, reduced social interaction is widely interpreted as reflecting increased anxiety. However, it can not be excluded from social interaction experiments that changes in sociability reflect other aspects of social behavior, such as social reward, or the subjective interpretation of social signals, that might also be affected by adolescent cannabinoid exposure. For instance, we have recently shown that the endocannabinoid system modulates the most abundant and rewarding form of social interaction displayed by adolescent mammals, that is social play behavior (Trezza et al., 2010). In particular, we found that systemic administration of indirect cannabinoid receptor agonists, i.e., drugs that increase endocannabinoid signaling by interfering with endocannabinoid deactivation, enhances social play, through interaction with opioid and dopaminergic neurotransmission (Trezza and Vanderschuren, 2008a,b, 2009). This suggests that during social play, endocannabinoids are released in brain areas mediating this behavior. Increased endocannabinoid activity might facilitate social play, so that drugs that prevent endocannabinoid deactivation likely enhance social play by magnifying the ongoing endocannabinoid tone. In contrast, we have also previously shown that stimulation of $\mathrm{CB}_{1}$ cannabinoid receptors throughout the brain using the cannabinoid receptor agonist WIN55,212-2 or the stable analog of anandamide, (R)methanandamide reduced social play (Trezza and Vanderschuren, 2008a,b, 2009). Therefore, it appears from these studies that the effects of cannabinoid drugs on social behavior differ according to the way the endocannabinoid system is targeted: drugs that prevent endocannabinoid deactivation enhance rewarding aspects of social interactions by magnifying ongoing endocannabinoid tone; conversely, drugs that directly activate cannabinoid receptors in multiple brain areas reduce sociability, perhaps by disrupting cognitive functions necessary to perform adequate social interactions (Egerton et al., 2006).

\section{DEPRESSIVE-LIKE BEHAVIORS}

Alongside changes in anxiety-related and social behaviors, other facets of emotionality are also affected by adolescent cannabinoid exposure. Thus, chronic treatment with both synthetic and natural cannabinoid agonists resulted in behavioral despair in adulthood, assessed as increased immobility in the forced swimming test, and anhedonia, measured as decreased sucrose preference in the sucrose-preference test (Rubino et al., 2008; Bambico et al., 2010; Realini et al., 2011). Other measures of anhedonia, such as impairment of progressive-ratio instrumental responding for food rewards and changes in sleep-wake cycle have also been reported following adolescent cannabinoid exposure (Schneider and Koch, 2003, 2005). Interestingly, as already reported for cannabis-induced cognitive impairments, the depression-like phenotype did not develop when the chronic cannabinoid administration was performed in older animals (Schneider and Koch, 2003, 2005; Bambico et al., 2010; Realini et al., 2011), confirming that the adult brain is less susceptible to the deleterious impact of chronic cannabinoid exposure.

As for the neural substrates underlying the depressive-like behaviors induced by adolescent cannabinoid exposure, electrophysiological recordings revealed that adolescent but not adult chronic cannabinoid treatment attenuated serotonergic neurotransmission in the dorsal raphe nucleus, while it induced a significant increase in noradrenergic neurotransmission in the locus coeruleus (Bambico etal., 2010). It has recently been 
proposed that the endocannabinoid system regulates affective homeostasis by interacting with monoaminergic neurotransmission (for review, see Bambico et al., 2009). Thus, activation of cannabinoid receptors by cannabinoid receptor agonists modulates serotonin (Gobbi et al., 2005; Palazzo et al., 2006; Bambico et al., 2007) and noradrenaline (Gobbi et al., 2005; Oropeza et al., 2005, 2007) activity. $\mathrm{CB}_{1}$ receptors are expressed on serotonergic neurons in the dorsal raphe nucleus (Elphick and Egetova, 2000; Haring et al., 2007) as well as on noradrenergic neurons in the locus coeruleus (Oropeza et al., 2007). Furthermore, they are highly expressed in limbic mood-regulatory brain areas innervated by these nuclei, such as the amygdala (for review, see Bambico and Gobbi, 2008; Bambico et al., 2009). During adolescence, serotonergic, noradrenergic, and cannabinoid neurotransmission undergo critical changes (Spear, 2000; Schneider, 2008). Thus, chronic cannabinoid exposure during adolescence may interfere with the cross-talk between these neural systems, eventually leading to persistent affective dysfunctions.

Interestingly, it has been shown that the depression-like phenotype displayed by adult rats treated with cannabinoid drugs during adolescence was paralleled by changes in other biochemical parameters linked to depression, such as decreased CREB activation in the prefrontal cortex and hippocampus, increased CREB activation and dynorphin levels in the nucleus accumbens, decreased neurogenesis in the dentate gyrus of the hippocampus, likely triggered by a long-lasting impairment of $\mathrm{CB}_{1}$ receptor signaling in the ventral tegmental area, amygdala, and nucleus accumbens (Rubino et al., 2008; Realini et al., 2011; Rubino and Parolaro, 2011). Since endocannabinoid neurotransmission in these brain areas is fundamental for normal emotional behavior and stress responses (Viveros et al., 2005; Laviolette and Grace, 2006; Zanettini et al., 2011), then changes in cannabinoid receptor function induced by adolescent cannabinoid exposure might underlie the altered emotional responses in adulthood.

\section{SUMMARY}

Altogether, the preclinical studies currently available show that prenatal and adolescent cannabinoid exposure affects different aspects of emotional reactivity, from early developmental ages till adulthood. In particular, it appears from preclinical studies that the outcome of developmental cannabinoid exposure on emotional reactivity later in life might depend on the specific component of emotionality taxed in the different behavioral tests. For instance, anxiety-related behaviors in tests that depend on spontaneous, exploratory behavior, such as the elevated plus-maze and open field tests, appear be more resistant to the long-term consequences of cannabinoid exposure. On the other hand, the anxiety-related measures in the novelty-suppressed feeding test, that depends on appetitive drive, and the reduction in social behavior observed in the social interaction test appear to be particularly sensitive to developmental cannabinoid exposure. The differences

\section{REFERENCES}

Akirav, I. (2011). The role of cannabinoids in modulating emotional and non-emotional memory processes in the hippocampus.
Front. Behav. Neurosci. 5:34. doi: 10.3389/fnbeh.2011.00034

Ameri, A. (1999). The effects of cannabinoids on the brain. Prog. Neurobiol. 58, 315-348.

observed at the behavioral level might also be the result of the different neuroanatomical and molecular correlates involved in each behavioral test. The changes in anxiety- and depressive-like behaviors and the altered sociability induced by developmental cannabinoid exposure might, in turn, affect the ability of the subject to cope with every day challenges and with fellow group members. This hypothesis, however, needs to be further investigated.

\section{CONCLUSIONS}

The endocannabinoid system plays a relevant role in brain organization during pre- and post-natal life. In Western countries, $C$. sativa preparations are among the illicit drugs most commonly used by young people, including pregnant women. Therefore, understanding the long-lasting consequences of cannabis exposure on the developing brain is an important issue. The clinical findings currently available suggest an association between developmental cannabis exposure and executive dysfunctions. Furthermore, cannabis exposure during the prenatal/perinatal and adolescent periods has been shown to induce subtle changes in emotionality that may persist into adulthood. Although there is some consistency in the clinical literature, the very limited number of findings emphasizes the need for further, well-controlled follow-up studies in this area. Relevant information is available from preclinical studies, demonstrating that even low to moderate doses of cannabinoids, when administered during particular periods of brain development, can have profound consequences for brain maturation, leading to long-lasting alterations of cognitive functions and emotional behaviors. Although there is still scarce information about the neurobiological substrates of the observed behavioral alterations, it appears that developmental cannabinoid exposure induces changes in the endocannabinoid system and in other neurotransmitter systems that are already functional at early developmental ages. These alterations may disrupt the integrity of mood- and cognition-regulating brain circuits, thus inducing long-lasting emotional and cognitive disturbances.

Multiple experimental approaches, including genetics, molecular biology, pharmacology, neuroanatomy, and neurophysiology, in both preclinical and clinical settings should be encouraged in the near future to further clarify the potential relationship between developmental cannabis exposure and long-lasting neurofunctional outcomes.

\section{ACKNOWLEDGMENTS}

Supported by Marie Curie Career Reintegration Grant No 293589 (Seventh Framework Programme) and Veni Grant No 91611052 from ZonMW (The Netherlands Organisation for Health Research and Development) to Viviana Trezza, and by grants from Ministero dell'Istruzione, Università e Ricerca PRIN 2009 (to Vincenzo Cuomo) and from Sapienza University "Progetti di Ricerca di Università 2010" (to Vincenzo Cuomo and Patrizia Campolongo).

Andersen, S. L. (2003). Trajectories of brain development: point of vulnerability or window of opportunity? Neurosci. Biobehav. Rev. 27, 3-18.
Antonelli, T., Tanganelli, S., Tomasini, M. C., Finetti, S., Trabace, L., Steardo, L., Sabino, V., Carratu, M. R., Cuomo, V., and Ferraro, L. (2004). Long-term effects on cortical glutamate release 
induced by prenatal exposure to the cannabinoid receptor agonist (R)-(+)-[2,3-dihydro-5-methyl3-(4-morpholinyl-methyl)pyrrolo [1,2,3-de]-1,4-benzoxazin-6-yl]-1naphthalenylmethanone: an in vivo microdialysis study in the awake rat. Neuroscience 124, 367-375.

Antonelli, T., Tomasini, M. C., Tattoli, M., Cassano, T., Finetti, S., Mazzoni, E., Trabace, L., Carratu, M. R., Cuomo, V., Tanganelli, S., and Ferraro, L. (2006). Prenatal exposure to the cannabinoid receptor agonist WIN 55,212-2 and carbon monoxide reduces extracellular glutamate levels in primary rat cerebral cortex cell cultures. Neurochem. Int. 49, 568-576.

Antonelli, T., Tomasini, M. C., Tattoli, M., Cassano, T., Tanganelli, S., Finetti, S., Mazzoni, E., Trabace, L., Steardo, L., Cuomo, V., and Ferraro, L. (2005). Prenatal exposure to the CB1 receptor agonist WIN 55,212-2 causes learning disruption associated with impaired cortical NMDA receptor function and emotional reactivity changes in rat offspring. Cereb. Cortex 15, 2013-2020.

Arseneault, L., Cannon, M., Poulton, R., Murray, R., Caspi, A., and Moffitt, T. E. (2002). Cannabis use in adolescence and risk for adult psychosis: longitudinal prospective study. BMJ 325, 1212-1213.

Baek, J., Zheng, Y., Darlington, C. L., and Smith, P. F. (2009). The CB1 receptor agonist, WIN 55,2122, dose-dependently disrupts object recognition memory in adult rats. Neurosci. Lett. 464, 71-73.

Bambico, F. R., Duranti, A., Tontini, A., Tarzia, G., and Gobbi, G. (2009). Endocannabinoids in the treatment of mood disorders: evidence from animal models. Curr. Pharm. Des. 15, 1623-1646.

Bambico, F. R., and Gobbi, G. (2008). The cannabinoid CB1 receptor and the endocannabinoid anandamide: possible antidepressant targets. Expert Opin. Ther. Targets 12, 1347-1366.

Bambico, F. R., Katz, N., Debonnel, G., and Gobbi, G. (2007). Cannabinoids elicit antidepressantlike behavior and activate serotonergic neurons through the medial prefrontal cortex. J. Neurosci. 27, 11700-11711.

Bambico, F. R., Nguyen, N. T., Katz, N., and Gobbi, G. (2010). Chronic exposure to cannabinoids during adolescence but not during adulthood impairs emotional behaviour and monoaminergic neurotransmission. Neurobiol. Dis. 37, 641-655.
Belue, R. C., Howlett, A. C., Westlake, T. M., and Hutchings, D. E. (1995). The ontogeny of cannabinoid receptors in the brain of postnatal and aging rats. Neurotoxicol. Teratol. 17, 25-30.

Bermudez-Silva, F. J., Viveros, M. P., Mcpartland, J. M., and Rodriguez de Fonseca, F. (2010). The endocannabinoid system, eating behavior and energy homeostasis: the end or a new beginning? Pharmacol. Biochem. Behav. 95, 375-382.

Berrendero, F., Garcia-Gil, L., Hernandez, M. L., Romero, J., Cebeira, M., De Miguel, R., Ramos, J. A., and Fernandez-Ruiz, J. J. (1998). Localization of mRNA expression and activation of signal transduction mechanisms for cannabinoid receptor in rat brain during fetal development. Development 125, 3179-3188.

Berrendero, F., Sepe, N., Ramos, J. A., Di Marzo, V., and Fernandez-Ruiz, J. J. (1999). Analysis of cannabinoid receptor binding and mRNA expression and endogenous cannabinoid contents in the developing rat brain during late gestation and early postnatal period. Synapse 33, 181-191.

Biscaia, M., Marin, S., Fernandez, B., Marco, E. M., Rubio, M., Guaza, C., Ambrosio, E., and Viveros, M. P. (2003). Chronic treatment with CP 55,940 during the peri-adolescent period differentially affects the behavioural responses of male and female rats in adulthood. Psychopharmacology (Berl.) 170, 301308.

Bonnin, A., De Miguel, R., Hernandez, M. L., Ramos, J. A., and FernandezRuiz, J. J. (1995). The prenatal exposure to delta 9-tetrahydrocannabinol affects the gene expression and the activity of tyrosine hydroxylase during early brain development. Life Sci. 56, 2177-2184.

Bonnin, A., De Miguel, R., RodriguezManzaneque, J. C., Fernandez-Ruiz, J. J., Santos, A., and Ramos, J. A. (1994). Changes in tyrosine hydroxylase gene expression in mesencephalic catecholaminergic neurons of immature and adult male rats perinatally exposed to cannabinoids. Brain Res. Dev. Brain Res. 81, 147-150.

Bortolato, M., Campolongo, P., Mangieri, R. A., Scattoni, M. L., Frau, R., Trezza, V., La Rana, G., Russo, R., Calignano, A., Gessa, G. L., Cuomo, V., and Piomelli, D. (2006). Anxiolytic-like properties of the anandamide transport inhibitor AM404. Neuropsychopharmacology 31, 2652-2659.

Bossong, M. G., and Niesink, R. J. (2011). Adolescent brain maturation, the endogenous cannabinoid system and the neurobiology of cannabisinduced schizophrenia. Prog. Neurobiol. 92, 370-385.

Branchi, I., Campolongo, P., and Alleva, E. (2004). Scopolamine effects on ultrasonic vocalization emission and behavior in the neonatal mouse. Behav. Brain Res. 151, 9-16.

Branchi, I., Santucci, D., and Alleva, E. (2001). Ultrasonic vocalisation emitted by infant rodents: a tool for assessment of neurobehavioural development. Behav. Brain Res. 125, 49-56.

Campolongo, P., Roozendaal, B., Trezza, V., Cuomo, V., Astarita, G., Fu, J., McGaugh, J. L., and Piomelli, D. (2009a). Fat-induced satiety factor oleoylethanolamide enhances memory consolidation. Proc. Natl. Acad. Sci. U.S.A. 106, 8027-8031.

Campolongo, P., Roozendaal, B., Trezza, V., Hauer, D., Schelling, G., Mcgaugh J. L., and Cuomo, V. (2009b). Endocannabinoids in the rat basolateral amygdala enhance memory consolidation and enable glucocorticoid modulation of memory. Proc. Natl. Acad. Sci. U.S.A. 106, 4888-4893.

Campolongo, P., Trezza, V., Palmery, M., Trabace, L., and Cuomo, V. (2009c). Developmental exposure to cannabinoids causes subtle and enduring neurofunctional alterations. Int. Rev. Neurobiol. 85, 117-133.

Campolongo, P., Trezza, V., Cassano, T., Gaetani, S., Morgese, M. G., Ubaldi, M., Soverchia, L., Antonelli, T., Ferraro, L., Massi, M., Ciccocioppo, R., and Cuomo, V. (2007). Perinatal exposure to delta-9tetrahydrocannabinol causes enduring cognitive deficits associated with alteration of cortical gene expression and neurotransmission in rats. Addict. Biol. 12, 485-495.

Campolongo, P., Trezza, V., Ratano, P., Palmery, M., and Cuomo, V. (2010). Developmental consequences of perinatal cannabis exposure: behavioral and neuroendocrine effects in adult rodents. Psychopharmacology (Berl.) 214, 5-15.

Castaldo, P., Magi, S., Cataldi, M., Arcangeli, S., Lariccia, V., Nasti, A. A., Ferraro, L., Tomasini, M. C., Antonelli, T., Cassano, T., Cuomo, V., and Amoroso, S. (2010). Altered regulation of glutamate release and decreased functional activity and expression of GLT1 and GLAST glutamate transporters in the hippocampus of adolescent rats perinatally exposed to Delta(9)-THC. Pharmacol. Res. 61, 334-341.

Castaldo, P., Magi, S., Gaetani, S., Cassano, T., Ferraro, L., Antonelli, T.,
Amoroso, S., and Cuomo, V. (2007). Prenatal exposure to the cannabinoid receptor agonist WIN 55,212-2 increases glutamate uptake through overexpression of GLT1 and EAAC1 glutamate transporter subtypes in rat frontal cerebral cortex. Neuropharmacology 53, 369-378.

Castellano, C., Rossi-Arnaud, C., Cestari, V., and Costanzi, M. (2003). Cannabinoids and memory: animal studies. Curr. Drug Targets CNS Neurol. Disord. 2, 389-402.

Castelli, M. P., Paola Piras, A., D'agostino, A., Pibiri, F., Perra, S., Gessa, G. L., Maccarrone, M., and Pistis, M. (2007). Dysregulation of the endogenous cannabinoid system in adult rats prenatally treated with the cannabinoid agonist WIN 55,212-2. Eur. J. Pharmacol. 573, 11-19.

Cha, Y. M., Jones, K. H., Kuhn, C. M., Wilson, W. A., and Swartzwelder, $\mathrm{H}$. S. (2007). Sex differences in the effects of delta9-tetrahydrocannabinol on spatial learning in adolescent and adult rats. Behav. Pharmacol. 18, 563-569.

Cha, Y. M., White, A. M., Kuhn, C. M., Wilson, W. A., and Swartzwelder, H. S. (2006). Differential effects of delta9-THC on learning in adolescent and adult rats. Pharmacol. Biochem. Behav. 83, 448-455.

Chevaleyre, V., Takahashi, K. A., and Castillo, P. E. (2006). Endocannabinoid-mediated synaptic plasticity in the CNS. Annu. Rev. Neurosci. 29, 37-76.

Cimadevilla, J. M., Kaminsky, Y., Fenton, A., and Bures, J. (2000). Passive and active place avoidance as a tool of spatial memory research in rats. J. Neurosci. Methods 102 , 155-164.

Compton, D. R., Gold, L. H., Ward, S. J., Balster, R. L., and Martin, B. R. (1992). Aminoalkylindole analogs: cannabimimetic activity of a class of compounds structurally distinct from delta 9-tetrahydrocannabinol. J. Pharmacol. Exp. Ther. 263, 1118 1126.

Costa, L. G., Steardo, L., and Cuomo, V. (2004). Structural effects and neurofunctional sequelae of developmental exposure to psychotherapeutic drugs: experimental and clinical aspects. Pharmacol. Rev. 56, 103-147.

Cuomo, V., De Salvia, M. A., Maselli, M. A., Santo, L., and Cagiano, R. (1987). Ultrasonic calling in rodents: a new experimental approach in behavioural toxicology. Neurotoxicol. Teratol. 9, 157-160.

Davies, S. N., Pertwee, R. G., and Riedel, G. (2002). Functions of cannabinoid 
receptors in the hippocampus. $\mathrm{Neu}$ ropharmacology 42, 993-1007.

Day, N., Cornelius, M., Goldschmidt, L., Richardson, G., Robles, N., and Taylor, P. (1992). The effects of prenatal tobacco and marijuana use on offspring growth from birth through 3 years of age. Neurotoxicol. Teratol. 14, 407-414.

Day, N. L., Richardson, G. A., Goldschmidt, L., Robles, N., Taylor, P. M., Stoffer, D. S., Cornelius, M. D., and Geva, D. (1994). Effect of prenatal marijuana exposure on the cognitive development of offspring at age three. Neurotoxicol. Teratol. 16, 169-175.

Degenhardt, L., Hall, W., and Lynskey, M. (2003). Exploring the association between cannabis use and depression. Addiction 98, 1493-1504.

de Graaf, R., Radovanovic, M., Van Laar, M., Fairman, B., Degenhardt, L., Aguilar-Gaxiola, S., Bruffaerts, R., De Girolamo, G., Fayyad, J., Gureje, O., Haro, J. M., Huang, Y., Kostychenko, S., Lepine, J. P., Matschinger, H., Mora, M. E., Neumark, Y., Ormel, J., Posada-Villa, J., Stein, D. J., Tachimori, H., Wells, J. E., and Anthony, J. C. (2010). Early cannabis use and estimated risk of later onset of depression spells: epidemiologic evidence from the population-based World Health Organization World Mental Health Survey Initiative. Am. J. Epidemiol. 172, 149-159.

De Petrocellis, L., and Di Marzo, V. (2009). An introduction to the endocannabinoid system: from the early to the latest concepts. Best Pract. Res. Clin. Endocrinol. Metab. 23, 1-15.

Di Forti, M., Morrison, P. D., Butt, A., and Murray, R. M. (2007). Cannabis use and psychiatric and cognitive disorders: the chicken or the egg? Curr. Opin. Psychiatry 20, 228-234.

Di Marzo, V. (2009). The endocannabinoid system: its general strategy of action, tools for its pharmacological manipulation and potential therapeutic exploitation. Pharmacol. Res. 60, 77-84.

Di Marzo, V., De Petrocellis, L., and Bisogno, T. (2005). The biosynthesis, fate and pharmacological properties of endocannabinoids. Handb. Exp. Pharmacol. 168, 147-185.

Egerton, A., Allison, C., Brett, R. R., and Pratt, J. A. (2006). Cannabinoids and prefrontal cortical function: insights from preclinical studies. Neurosci. Biobehav. Rev. 30, 680-695.

Ehrenreich, H., Rinn, T., Kunert, H. J., Moeller, M. R., Poser, W., Schilling, L., Gigerenzer, G., and Hoehe, M. R. (1999). Specific attentional dysfunction in adults following early start of cannabis use. Psychopharmacology (Berl.) 142, 295-301.

Elphick, M. R., and Egetova, M. (2000). Cannabinoid signalling in the nervous system: comparative localization of $\mathrm{CB} 1$ receptors and fatty acid amide hydrolase in rat and mouse brain. Eur. J. Neurosci. 12, 68.

Farrell, W. J., and Alberts, J. R. (2002). Stimulus control of maternal responsiveness to Norway rat (Rattus norvegicus) pup ultrasonic vocalizations. J. Comp. Psychol. 116, 297-307.

Fattore, L., and Fratta, W. (2011). Beyond THC: the new generation of cannabinoid designer drugs. Front. Behav. Neurosci. 5:60. doi: 10.3389/fnbeh.2011.00060

Fergusson, D. M., Horwood, L. J., and Swain-Campbell, N. (2002). Cannabis use and psychosocial adjustment in adolescence and young adulthood. Addiction 97, 1123-1135.

Fergusson, D. M., Horwood, L. J., and Swain-Campbell, N. R. (2003). Cannabis dependence and psychotic symptoms in young people. Psychol. Med. 33, 15-21.

Fernandez-Ruiz, J., Berrendero, F., Hernandez, M. L., and Ramos, J. A. (2000). The endogenous cannabinoid system and brain development. Trends Neurosci. 23, 14-20.

Ferraro, L., Tomasini, M. C., Beggiato, S., Gaetani, S., Cassano, T., Cuomo, V., Amoroso, S., Tanganelli, S., and Antonelli, T. (2009). Short- and long-term consequences of prenatal exposure to the cannabinoid agonist WIN55,212-2 on rat glutamate transmission and cognitive functions. $J$. Neural Transm. 116, 1017-1027.

File, S. E., and Seth, P. (2003). A review of 25 years of the social interaction test. Eur. J. Pharmacol. 463, 35-53.

French, E. D., Dillon, K., and Wu, X. (1997). Cannabinoids excite dopamine neurons in the ventral tegmentum and substantia nigra. Neuroreport 8, 649-652.

Freund, T. F., Katona, I., and Piomelli, D. (2003). Role of endogenous cannabinoids in synaptic signaling. Physiol. Rev 83, 1017-1066.

Fride, E. (2004). The endocannabinoid$\mathrm{CB}(1)$ receptor system in pre- and postnatal life. Eur. J. Pharmacol. 500, 289-297.

Fried, P. A. (2002a). Adolescents prenatally exposed to marijuana: examination of facets of complex behaviors and comparisons with the influence of in utero cigarettes. J. Clin. Pharmacol. 42, 97S-102S.

Fried, P. A. (2002b). Conceptual issues in behavioral teratology and their application in determining longterm sequelae of prenatal marihuana exposure. J. Child Psychol. Psychiatry 43, 81-102.

Fried, P. A., and Smith, A. M. (2001). A literature review of the consequences of prenatal marihuana exposure. An emerging theme of a deficiency in aspects of executive function. Neurotoxicol. Teratol. 23, 1-11.

Fried, P. A., and Watkinson, B. (1988). 12- and 24-month neurobehavioural follow-up of children prenatally exposed to marihuana, cigarettes and alcohol. Neurotoxicol. Teratol. 10, 305-313.

Fried, P. A., and Watkinson, B. (1990). 36- and 48-month neurobehavioral follow-up of children prenatally exposed to marijuana, cigarettes, and alcohol. J. Dev. Behav. Pediatr. 11, 49-58.

Fried, P. A., Watkinson, B., and Gray, R. (1998). Differential effects on cognitive functioning in 9- to 12-year olds prenatally exposed to cigarettes and marihuana. Neurotoxicol. Teratol. 20, 293-306.

Fried, P. A., Watkinson, B., and Gray, R. (2003). Differential effects on cognitive functioning in 13- to 16-yearolds prenatally exposed to cigarettes and marihuana. Neurotoxicol. Teratol. 25, 427-436.

Galve-Roperh, I., Aguado, T., Rueda, D., Velasco, G., and Guzman, M. (2006). Endocannabinoids: a new family of lipid mediators involved in the regulation of neural cell development. Curr. Pharm. Des. 12, 2319-2325.

Garcia-Gil, L., De Miguel, R., Munoz, R. M., Cebeira, M., Villanua, M. A., Ramos, J. A., and FernandezRuiz, J. J. (1997). Perinatal delta(9)tetrahydrocannabinol exposure alters the responsiveness of hypothalamic dopaminergic neurons to dopamineacting drugs in adult rats. Neurotoxicol. Teratol. 19, 477-487.

Garcia-Gil, L., De Miguel, R., Romero, J., Perez, A., Ramos, J. A., and Fernandez-Ruiz, J. J. (1999a). Perinatal delta9-tetrahydrocannabinol exposure augmented the magnitude of motor inhibition caused by $\operatorname{GABA}(\mathrm{B})$, but not $\operatorname{GABA}(\mathrm{A})$, receptor agonists in adult rats. Neurotoxicol. Teratol. 21, 277-283.

Garcia-Gil, L., Romero, J., Ramos, J. A., and Fernandez-Ruiz, J. J. (1999b). Cannabinoid receptor binding and mRNA levels in several brain regions of adult male and female rats perinatally exposed to delta9tetrahydrocannabinol. Drug Alcohol Depend. 55, 127-136.

Gobbi, G., Bambico, F. R., Mangieri, R., Bortolato, M., Campolongo, P., Solinas, M., Cassano, T., Morgese, M. G., Debonnel, G.,
Duranti, A., Tontini, A., Tarzia, G., Mor, M., Trezza, V., Goldberg, S. R., Cuomo, V., and Piomelli, D. (2005). Antidepressant-like activity and modulation of brain monoaminergic transmission by blockade of anandamide hydrolysis. Proc. Natl. Acad. Sci. U.S.A. 102, 18620-18625.

Goldschmidt, L., Richardson, G. A. Cornelius, M. D., and Day, N. L. (2004). Prenatal marijuana and alcohol exposure and academic achievement at age 10. Neurotoxicol. Teratol. 26, 521-532.

Gray, K. A., Day, N. L., Leech, S., and Richardson, G. A. (2005). Prenatal marijuana exposure: effect on child depressive symptoms at ten years of age. Neurotoxicol. Teratol. 27, 439448.

Hall, W., and Degenhardt, L. (2009). Adverse health effects of non-medical cannabis use. Lancet 374, 1383-1391.

Haller, J., Bakos, N., Szirmay, M., Ledent, C., and Freund, T. F. (2002). The effects of genetic and pharmacological blockade of the CB1 cannabinoid receptor on anxiety. Eur. J. Neurosci. 16, 1395-1398.

Haller, J., Varga, B., Ledent, C., Barna, I., and Freund, T. F. (2004a). Contextdependent effects of CB1 cannabinoid gene disruption on anxiety-like and social behaviour in mice. Eur. J. Neurosci. 19, 1906-1912.

Haller, J., Varga, B., Ledent, C., and Freund, T. F. (2004b). CB1 cannabinoid receptors mediate anxiolytic effects: convergent genetic and pharmacological evidence with CB1-specific agents. Behav. Pharmacol. 15, 299 304.

Hampson, R. E., Mu, J., and Deadwyler, S. A. (2000). Cannabinoid and kappa opioid receptors reduce potassium $\mathrm{K}$ current via activation of $\mathrm{G}(\mathrm{s})$ proteins in cultured hippocampal neurons. $J$. Neurophysiol. 84, 2356-2364.

Haring, M., Marsicano, G., Lutz, B., and Monory, K. (2007). Identification of the cannabinoid receptor type 1 in serotonergic cells of raphe nuclei in mice. Neuroscience 146, 1212-1219.

Harkany, T., Guzman, M., GalveRoperh, I., Berghuis, P., Devi, L. A., and Mackie, K. (2007). The emerging functions of endocannabinoid signaling during CNS development. Trends Pharmacol. Sci. 28, 83-92.

Harte, L. C., and Dow-Edwards, D. (2010). Sexually dimorphic alterations in locomotion and reversal learning after adolescent tetrahydrocannabinol exposure in the rat. $\mathrm{Neu}$ rotoxicol. Teratol. 32, 515-524.

Hayatbakhsh, M. R., Najman, J. M., Jamrozik, K., Mamun, A. A., Alati, R., and Bor, W. (2007). Cannabis 
and anxiety and depression in young adults: a large prospective study. $J$. Am. Acad. Child Adolesc. Psychiatry 46, 408-417.

Hermann, H., Marsicano, G., and Lutz, B. (2002). Coexpression of the cannabinoid receptor type 1 with dopamine and serotonin receptors in distinct neuronal subpopulations of the adult mouse forebrain. Neuroscience 109, 451-460.

Higuera-Matas, A., Botreau, F., Miguens, M., Del Olmo, N., Borcel, E., Perez-Alvarez, L., GarciaLecumberri, C., and Ambrosio, E. (2009). Chronic periadolescent cannabinoid treatment enhances adult hippocampal PSA-NCAM expression in male Wistar rats but only has marginal effects on anxiety, learning and memory. Pharmacol. Biochem. Behav. 93, 482-490.

Insel, T. R., Hill, J. L., and Mayor, R. B. (1986). Rat pup ultrasonic isolation calls: possible mediation by the benzodiazepine receptor complex. Pharmacol. Biochem. Behav. 24, 1263-1267.

Iversen, L. (2003). Cannabis and the brain. Brain 126, 1252-1270.

Jacobsen, L. K., Mencl, W. E., Westerveld, M., and Pugh, K. R. (2004). Impact of cannabis use on brain function in adolescents. Ann. N.Y. Acad. Sci. 1021, 384-390.

Jacobsen, L. K., Pugh, K. R., Constable, R. T., Westerveld, M., and Mencl, W. E. (2007). Functional correlates of verbal memory deficits emerging during nicotine withdrawal in abstinent adolescent cannabis users. Biol. Psychiatry 61, 31-40.

Jager, G., and Ramsey, N. F. (2008). Long-term consequences of adolescent cannabis exposure on the development of cognition, brain structure and function: an overview of animal and human research. Curr. Drug Abuse Rev. 1, 114-123.

Kathuria, S., Gaetani, S., Fegley, D., Valino, F., Duranti, A., Tontini, A., Mor, M., Tarzia, G., La Rana, G., Calignano, A., Giustino, A., Tattoli, M., Palmery, M., Cuomo, V., and Piomelli, D. (2003). Modulation of anxiety through blockade of anandamide hydrolysis. Nat. Med. 9, 76-81.

Katona, I., Rancz, E. A., Acsady, L., Ledent, C., Mackie, K., Hajos, N., and Freund, T. F. (2001). Distribution of CB1 cannabinoid receptors in the amygdala and their role in the control of GABAergic transmission. J. Neurosci. 21, 9506-9518.

Laviolette, S. R., and Grace, A. A. (2006). The roles of cannabinoid and dopamine receptor systems in neural emotional learning circuits: implications for schizophrenia and addiction. Cell. Mol. Life Sci. 63 , 1597-1613.

Lee, K. S., Clough, A. R., Jaragba, M. J., Conigrave, K. M., and Patton, G. C. (2008). Heavy cannabis use and depressive symptoms in three Aboriginal communities in Arnhem Land, Northern Territory. Med. J. Aust. 188, 605-608.

Leech, S. L., Larkby, C. A., Day, R., and Day, N. L. (2006). Predictors and correlates of high levels of depression and anxiety symptoms among children at age 10. J. Am. Acad. Child Adolesc. Psychiatry 45, 223-230.

Leweke, F. M., and Schneider, M. (2011). Chronic pubertal cannabinoid treatment as a behavioural model for aspects of schizophrenia: effects of the atypical antipsychotic quetiapine. Int. J. Neuropsychopharmacol. 14, 43-51.

Lutz, B. (2009). Endocannabinoid signals in the control of emotion. Curr. Opin. Pharmacol. 9, 46-52.

Macleod, J., Davey Smith, G., Hickman, M., and Egger, M. (2007). Cannabis and psychosis. Lancet 370, 1539; author reply 1539-1540.

Macleod, J., Oakes, R., Copello, A., Crome, I., Egger, M., Hickman, M., Oppenkowski, T., Stokes-Lampard, H., and Davey Smith, G. (2004). Psychological and social sequelae of cannabis and other illicit drug use by young people: a systematic review of longitudinal, general population studies. Lancet 363, 1579-1588.

Mangieri, R. A., and Piomelli, D. (2007). Enhancement of endocannabinoid signaling and the pharmacotherapy of depression. Pharmacol. Res. 56, 360-366.

Marco, E. M., Garcia-Gutierrez, M. S., Bermudez-Silva, F. J., Moreira, F. A., Guimaraes, F., Manzanares, J., and Viveros, M. P. (2011). Endocannabinoid system and psychiatry: in search of a neurobiological basis for detrimental and potential therapeutic effects. Front. Behav. Neurosci. 5:63. doi: 10.3389/fnbeh.2011.00063

Marco, E. M., and Viveros, M. P. (2009). The critical role of the endocannabinoid system in emotional homeostasis: avoiding excess and deficiencies. Mini Rev. Med. Chem. 9, 1407-1415.

Marsicano, G., and Lafenetre, P. (2009). Roles of the endocannabinoid system in learning and memory. Curr. Top. Behav. Neurosci. 1, 201-230.

Martin, M., Ledent, C., Parmentier, M., Maldonado, R., and Valverde, O. (2002). Involvement of CB1 cannabinoid receptors in emotional behaviour. Psychopharmacology (Berl.) 159, 379-387.

Mato, S., Del Olmo, E., and Pazos, A. (2003). Ontogenetic development of cannabinoid receptor expression and signal transduction functionality in the human brain. Eur. J. Neurosci. 17, 1747-1754.

Matsuda, L. A. (1997). Molecular aspects of cannabinoid receptors. Crit. Rev. Neurobiol. 11, 143-166.

McGaugh, J. L. (2002). Memory consolidation and the amygdala: a systems perspective. Trends Neurosci. 25, 456.

McGregor, I. S., Dastur, F. N., Mclellan, R. A., and Brown, R. E. (1996). Cannabinoid modulation of rat pup ultrasonic vocalizations. Eur. J. Pharmacol. 313, 43-49.

Mereu, G., Fa, M., Ferraro, L., Cagiano, R., Antonelli, T., Tattoli, M., Ghiglieri, V., Tanganelli, S., Gessa, G. L., and Cuomo, V. (2003). Prenatal exposure to a cannabinoid agonist produces memory deficits linked to dysfunction in hippocampal long-term potentiation and glutamate release. Proc. Natl. Acad. Sci. U.S.A. 100, 4915-4920.

Millan, M. J. (2003). The neurobiology and control of anxious states. Prog. Neurobiol. 70, 83-244.

Molina-Holgado, F., Amaro, A., Gonzalez, M. I., Alvarez, F. J., and Leret, M. L. (1996). Effect of maternal delta 9tetrahydrocannabinol on developing serotonergic system. Eur. J. Pharmacol. 316, 39-42.

Moore, T. H., Zammit, S., LingfordHughes, A., Barnes, T. R., Jones, P. B., Burke, M., and Lewis, G. (2007). Cannabis use and risk of psychotic or affective mental health outcomes: a systematic review. Lancet 370, 319328.

Moreira, F. A., Kaiser, N., Monory, K., and Lutz, B. (2008). Reduced anxietylike behaviour induced by genetic and pharmacological inhibition of the endocannabinoid-degrading enzyme fatty acid amide hydrolase (FAAH) is mediated by CB1 receptors. Neuropharmacology 54, 141-150.

Moreira, F. A., and Lutz, B. (2008) The endocannabinoid system: emotion, learning and addiction. Addict. Biol. 13, 196-212.

Murray, R. M., Morrison, P. D., Henquet, C., and Di Forti, M. (2007). Cannabis, the mind and society: the hash realities. Nat. Rev. Neurosci. 8 , 885-895.

Newsom, R. J., and Kelly, S. J. (2008). Perinatal delta-9-tetrahy drocannabinol exposure disrupts social and open field behavior in adult male rats. Neurotoxicol. Teratol. 30, 213-219.
NIDA. (2005). NIDA Research Monograph Series: Marijuana Abuse. Washington, DC: NIH.

Onaivi, E. S., Green, M. R., and Martin, B. R. (1990). Pharmacological characterization of cannabinoids in the elevated plus maze. J. Pharmacol. Exp. Ther. 253, 1002-1009.

Oropeza, V. C., Mackie, K., and Van Bockstaele, E. J. (2007). Cannabinoid receptors are localized to noradrenergic axon terminals in the rat frontal cortex. Brain Res. 1127, 36-44.

Oropeza, V. C., Page, M. E., and Van Bockstaele, E. J. (2005). Systemic administration of WIN 55,212 2 increases norepinephrine release in the rat frontal cortex. Brain Res. 1046 , 45-54.

O'Shea, M., McGregor, I. S., and Mallet, P. E. (2006). Repeated cannabinoid exposure during perinatal, adolescent or early adult ages produces similar longlasting deficits in object recognition and reduced social interaction in rats. J. Psychopharmacol. 20, 611-621.

O'Shea, M., Singh, M. E., McGregor, I. S., and Mallet, P. E. (2004). Chronic cannabinoid exposure produces lasting memory impairment and increased anxiety in adolescent but not adult rats. J. Psychopharmacol. 18, 502-508.

Pacher, P., Batkai, S., and Kunos, G. (2006). The endocannabinoid system as an emerging target of pharmacotherapy. Pharmacol. Rev. 58, 389-462.

Palazzo, E., De Novellis, V., Petrosino, S. Marabese, I., Vita, D., Giordano, C. Di Marzo, V., Mangoni, G. S., Rossi, F., and Maione, S. (2006). Neuropathic pain and the endocannabinoid system in the dorsal raphe: pharmacological treatment and interactions with the serotonergic system. Eur. J. Neurosci. 24, 2011-2020.

Pattij, T., Wiskerke, J., and Schoffelmeer, A. N. (2008). Cannabinoid modulation of executive functions. Eur. J. Pharmacol. 585, 458-463.

Patton, G. C., Coffey, C., Carlin, J. B., Degenhardt, L., Lynskey, M., and Hall, W. (2002). Cannabis use and mental health in young people: cohort study. BMJ 325, 1195-1198.

Pertwee, R. G. (1997). Pharmacology of cannabinoid CB1 and CB2 receptors. Pharmacol. Ther. 74, 129-180.

Petrosino, S., and Di Marzo, V. (2010). FAAH and MAGL inhibitors: therapeutic opportunities from regulating endocannabinoid levels. Curr. Opin. Investig. Drugs 11, 51-62.

Piomelli, D. (2003). The molecular logic of endocannabinoid signalling. Nat. Rev. Neurosci. 4, 873-884. 
Piomelli, D., Tarzia, G., Duranti, A., Tontini, A., Mor, M., Compton, T. R., Dasse, O., Monaghan, E. P., Parrott, J. A., and Putman, D. (2006). Pharmacological profile of the selective FAAH inhibitor KDS4103 (URB597). CNS Drug Rev. 12, 21-38.

Pope, H. G. Jr., Gruber, A. J., Hudson, J. I., Cohane, G., Huestis, M. A., and Yurgelun-Todd, D. (2003). Early-onset cannabis use and cognitive deficits: what is the nature of the association? Drug Alcohol Depend. 69, 303-310.

Quinn, H. R., Matsumoto, I., Callaghan, P. D., Long, L. E., Arnold, J. C., Gunasekaran, N., Thompson, M. R., Dawson, B., Mallet, P. E., Kashem, M. A., Matsuda-Matsumoto, H., Iwazaki, T., and McGregor, I. S. (2008). Adolescent rats find repeated $\operatorname{Delta}(9)$ THC less aversive than adult rats but display greater residual cognitive deficits and changes in hippocampal protein expression following exposure. Neuropsychopharmacology 33, 1113-1126.

Ranganathan, M., and D'Souza, D. C. (2006). The acute effects of cannabinoids on memory in humans: a review. Psychopharmacology (Berl.) 188, 425-444.

Realini, N., Rubino, T., and Parolaro, D. (2009). Neurobiological alterations at adult age triggered by adolescent exposure to cannabinoids. Pharmacol. Res. 60, 132-138.

Realini, N., Vigano, D., Guidali, C., Zamberletti, E., Rubino, T., and Parolaro, D. (2011). Chronic URB597 treatment at adulthood reverted most depressive-like symptoms induced by adolescent exposure to THC in female rats. Neuropharmacology 60, 235-243.

Riedel, G., and Davies, S. N. (2005). Cannabinoid function in learning, memory and plasticity. Handb. Exp. Pharmacol. 168, 445-477.

Rodriguez de Fonseca, F., Carrera, M. R., Navarro, M., Koob, G. F., and Weiss, F. (1997). Activation of corticotropinreleasing factor in the limbic system during cannabinoid withdrawal. Science 276, 2050-2054.

Rodriguez de Fonseca, F., Cebeira, M., Fernandez-Ruiz, J. J., Navarro, M., and Ramos, J. A. (1991). Effects of pre- and perinatal exposure to hashish extracts on the ontogeny of brain dopaminergic neurons. Neuroscience 43, 713-723.

Rodriguez de Fonseca, F., Ramos, J. A., Bonnin, A., and Fernandez-Ruiz, J. J. (1993). Presence of cannabinoid binding sites in the brain from early postnatal ages. Neuroreport 4, 135-138.
Rodriguez de Fonseca, F., Rubio, P., Menzaghi, F., Merlo-Pich, E., Rivier, J., Koob, G. F., and Navarro, M. (1996). Corticotropinreleasing factor (CRF) antagonist [DPhe12,Nle21,38,C alpha MeLeu37] CRF attenuates the acute actions of the highly potent cannabinoid receptor agonist HU-210 on defensivewithdrawal behavior in rats. J. Pharmacol. Exp. Ther. 276, 56-64.

Romero, J., Garcia-Palomero, E. Berrendero, F., Garcia-Gil, L., Hernandez, M. L., Ramos, J. A., and Fernandez-Ruiz, J. J. (1997). Atypical location of cannabinoid receptors in white matter areas during rat brain development. Synapse 26, 317-323.

Rubino, T., and Parolaro, D. (2008). Long lasting consequences of cannabis exposure in adolescence. Mol. Cell. Endocrinol. 286, S108-S113.

Rubino, T., and Parolaro, D. (2011). Sexually dimorphic effects of cannabinoid compounds on emotion and cognition. Front. Behav. Neurosci. 5:64. doi: 10.3389/fnbeh.2011.00064

Rubino, T., Realini, N., Braida, D. Alberio, T., Capurro, V., Vigano, D., Guidali, C., Sala, M., Fasano, M., and Parolaro, D. (2009a). The depressive phenotype induced in adult female rats by adolescent exposure to THC is associated with cognitive impairment and altered neuroplasticity in the prefrontal cortex. Neurotox. Res. 15, 291-302.

Rubino, T., Realini, N., Braida, D., Guidi, S., Capurro, V., Vigano, D., Guidali, C., Pinter, M., Sala, M., Bartesaghi, R., and Parolaro, D. (2009b). Changes in hippocampal morphology and neuroplasticity induced by adolescent THC treatment are associated with cognitive impairment in adulthood. Hippocampus 19, 763-772.

Rubino, T., Vigano, D., Realini, N., Guidali, C., Braida, D., Capurro, V., Castiglioni, C., Cherubino, F., Romualdi, P., Candeletti, S., Sala, M., and Parolaro, D. (2008). Chronic delta 9-tetrahydrocannabinol during adolescence provokes sex-dependent changes in the emotional profile in adult rats: behavioral and biochemical correlates. Neuropsychopharmacology 33, 2760-2771.

Rubino, T., Zamberletti, E., and Parolaro, D. (2011). Adolescent exposure to cannabis as a risk factor for psychiatric disorders. J Psychopharmacol. doi: 10.1177/0269881111405362

Schlicker, E., and Kathmann, M. (2001). Modulation of transmitter release via presynaptic cannabinoid receptors. Trends Pharmacol. Sci. 22, 565-572.

Schneider, M. (2008). Puberty as a highly vulnerable developmental period for the consequences of cannabis exposure. Addict. Biol. 13, 253-263.

Schneider, M., and Koch, M. (2003). Chronic pubertal, but not adult chronic cannabinoid treatment impairs sensorimotor gating, recognition memory, and the performance in a progressive ratio task in adult rats. Neuropsychopharmacology 28, 1760-1769.

Schneider, M., and Koch, M. (2005). Deficient social and play behavior in juvenile and adult rats after neonatal cortical lesion: effects of chronic pubertal cannabinoid treatment. Neuropsychopharmacology 30, 944-957.

Schneider, M., Schomig, E., and Leweke, F. M. (2008). Acute and chronic cannabinoid treatment differentially affects recognition memory and social behavior in pubertal and adult rats. Addict. Biol. 13, 345-357.

Schweinsburg, A. D., Brown, S. A., and Tapert, S. F. (2008). The influence of marijuana use on neurocognitive functioning in adolescents. Curr. Drug Abuse Rev. 1, 99-111.

Smith, A. M., Fried, P. A., Hogan, M. J., and Cameron, I. (2006). Effects of prenatal marijuana on visuospatial working memory: an fMRI study in young adults. Neurotoxicol. Teratol. 28, 286-295.

Solowij, N., and Pesa, N. (2010). Cognitive abnormalities and cannabis use. Rev. Bras. Psiquiatr. 32(Suppl. 1), S31-S40.

Spear, L. P. (2000). The adolescent brain and age-related behavioral manifestations. Neurosci. Biobehav. Rev. 24, 417-463.

Steckler, T., Drinkenburg, W. H., Sahgal, A., and Aggleton, J. P. (1998). Recognition memory in rats - II. Neuroanatomical substrates. Prog. Neurobiol. 54, 313-332.

Stefanis, N. C., Delespaul, P., Henquet, C., Bakoula, C., Stefanis, C. N., and Van Os, J. (2004). Early adolescent cannabis exposure and positive and negative dimensions of psychosis. Addiction 99, 1333-1341.

Substance Abuse and Mental Health Services Administration (SAMHSA). (2009). Results from the 2009 National Survey on Drug Use and Health, Vol. I, Summary of National Findings. Rockville, MD: SAMHSA.

Suenaga, T., and Ichitani, Y. (2008). Effects of hippocampal administration of a cannabinoid receptor agonist WIN 55,212-2 on spontaneous object and place recognition in rats. Behav. Brain Res. 190, 248-252.

Szabo, B., and Schlicker, E. (2005). Effects of cannabinoids on neurotransmission. Handb. Exp. Pharmacol. 168, 327-365.

Terzian, A. L., Drago, F., Wotjak, C. T., and Micale, V. (2011). The dopamine and cannabinoid interaction in the modulation of emotions and cognition: assessing the role of cannabinoid CB1 receptor in neurons expressing dopamine D1 receptors. Front. Behav. Neurosci. 5:49. doi: 10.3389/fnbeh.2011.00049

Trezza, V., Baarendse, P. J., and Vanderschuren, L. J. M. J. (2010). The pleasures of play: pharmacological insights into social reward mechanisms. Trends Pharmacol. Sci. 31, 463-469.

Trezza, V., Campolongo, P., Cassano, T., Macheda, T., Dipasquale, P., Carratu, M. R., Gaetani, S., and Cuomo, V. (2008a). Effects of perinatal exposure to delta-9-tetrahydrocannabinol on the emotional reactivity of the offspring: a longitudinal behavioral study in Wistar rats. Psychopharmacology (Berl.) 198, 529-537.

Trezza, V., Cuomo, V., and Vanderschuren, L. J. M. J. (2008b). Cannabis and the developing brain: insights from behavior. Eur. J. Pharmacol. 585, 441-452.

Trezza, V., Campolongo, P., and Vanderschuren, L. J. M. J. (2011). Evaluating the rewarding nature of social interactions in laboratory animals. Dev. Cogn. Neurosci. 1, 444-458.

Trezza, V., and Vanderschuren, L. J. M. J. (2008a). Bidirectional cannabinoid modulation of social behavior in adolescent rats. Psychopharmacology (Berl.) 197, 217-227.

Trezza, V., and Vanderschuren, L. J. M. J. (2008b). Cannabinoid and opioid modulation of social play behavior in adolescent rats: differential behavioral mechanisms. Eur. Neuropsychopharmacol. 18, 519-530.

Trezza, V., and Vanderschuren, L. J. M. J. (2009). Divergent effects of anandamide transporter inhibitors with different target selectivity on social play behavior in adolescent rats. J. Pharmacol. Exp. Ther. 328, 343-350.

Tsou, K., Brown, S., Sanudo-Pena, M. C., Mackie, K., and Walker, J. M. (1998). Immunohistochemical distribution of cannabinoid CB1 receptors in the rat central nervous system. Neuroscience 83, 393-411.

Tunving, K. (1985). Psychiatric effects of cannabis use. Acta Psychiatr. Scand. 72, 209-217. 
Vela, G., Fuentes, J. A., Bonnin, A., Fernandez-Ruiz, J., and RuizGayo, M. (1995). Perinatal exposure to delta 9-tetrahydrocannabinol (delta 9-THC) leads to changes in opioid-related behavioral patterns in rats. Brain Res. 680, 142-147.

Vela, G., Martin, S., Garcia-Gil, L., Crespo, J. A., Ruiz-Gayo, M., Javier Fernandez-Ruiz, J., GarciaLecumberri, C., Pelaprat, D., Fuentes, J. A., Ramos, J. A., and Ambrosio, E. (1998). Maternal exposure to delta9-tetrahydrocannabinol facilitates morphine self-administration behavior and changes regional binding to central mu opioid receptors in adult offspring female rats. Brain Res. 807, 101-109.

Vinod, K. Y., and Hungund, B. L. (2006). Cannabinoid-1 receptor: a novel target for the treatment of neuropsychiatric disorders. Expert Opin. Ther. Targets 10, 203-210.

Viveros, M. P., Marco, E. M., and File, S. E. (2005). Endocannabinoid system and stress and anxiety responses. Pharmacol. Biochem. Behav. 81, 331-342.

Wegener, N., and Koch, M. (2009). Behavioural disturbances and altered Fos protein expression in adult rats after chronic pubertal cannabinoid treatment. Brain Res. 1253, 81-91.

Williamson, E. M., and Evans, F. J. (2000). Cannabinoids in clinical practice. Drugs 60, 1303-1314.

Witkin, J. M., Tzavara, E. T., and Nomikos, G. G. (2005). A role for cannabinoid CB1 receptors in mood and anxiety disorders. Behav. Pharmacol. 16, 315-331.
Wotjak, C. T. (2005). Role of endogenous cannabinoids in cognition and emotionality. Mini Rev. Med. Chem. 5, 659-670.

Zanettini, C., Panlilio, L. V., Alicki, M., Goldberg, S. R., Haller, J., and Yasar, S. (2011). Effects of endocannabinoid system modulation on cognitive and emotional behavior. Front. Behav. Neurosci. 5:57. doi: 10.3389/fnbeh.2011.00057

Conflict of Interest Statement: The authors declare that the research was conducted in the absence of any commercial or financial relationships that could be construed as a potential conflict of interest.

Received: 21 November 2011; accepted: 04 January 2012; published online: 24 January 2012.
Citation: Trezza V, Campolongo $P$ Manduca A, Morena M, Palmery $M$, Vanderschuren LJMJ and Cuomo $V$ (2012) Altering endocannabinoid neurotransmission at critical developmental ages: impact on rodent emotionality and cognitive performance. Front. Behav. Neurosci. 6:2. doi: 10.3389/fnbeh.2012.00002

Copyright $\odot 2012$ Trezza, Campolongo, Manduca, Morena, Palmery, Vanderschuren and Cuomo. This is an openaccess article distributed under the term of the Creative Commons Attribution Non Commercial License, which permits non-commercial use, distribution, and reproduction in other forums, provided the original authors and source are credited. 